\title{
Antibacterial action of dipeptides containing an inhibitor of glucosamine-6-phosphate isomerase
}

\author{
Henryk Chmara, ${ }^{1}+$ Sławomir Milewski, ${ }^{1}$ Ryszard Andruszkiewicz, ${ }^{1}$ \\ Fiorenzo Mignini ${ }^{2}$ and Edward Borowski ${ }^{1}$
} Author for correspondence: Slawomir Milewski. Tel: +48 5834721 07. Fax: +48583472694.
e-mail: milewski@altis.chem.pg.gda.pl

1 Department of Pharmaceutical

Technology \&

Biochemistry, Technical

University of Gdańsk, $11 / 12$

Narutowicza Str, 80-952

Gdanisk, Poland

2 Department of Molecular, Animal \& Cell Biology, University of Camerino, 62032 Camerino, Italy

\begin{abstract}
Several dipeptides, containing the $\boldsymbol{N}^{3}$-(4-methoxyfumaroyl)-L-2,3diaminopropanoic acid (FMDP) moiety linked to protein and non-protein amino acids, exhibited a strong growth-inhibitory and bactericidal effect against Bacillus subtilis. FMDP-dipeptides were efficiently transported into bacterial cells by a di-tripeptide permease and subsequently cleaved by intracellular $\mathrm{Mn}^{2+} / \mathrm{Co}^{2+}$-dependent peptidases. Cleavage rates [0.1-5.6 $\mu \mathrm{mol} \mathrm{min}^{-1}$ ( $\mathrm{mg}$ protein)-1] were about two orders of magnitude lower than transport rates [40-200 $\left.\mathrm{mmol} \mathrm{min}^{-1}\left(\mathrm{mg}^{\mathrm{dry}} \mathrm{wt}\right)^{-1}\right]$. The released FMDP inactivated glucosamine-6-phosphate (GIcN-6-P) isomerase, an enzyme catalysing the first committed step in a biosynthetic pathway leading to amino sugar-nucleotide precursors of bacterial peptidoglycan. Inhibition of GICN-6-P isomerase precluded peptidoglycan biosynthesis and resulted in a strong bacteriolytic effect. Results of the studies on consequences of GICN-6-P isomerase inhibition upon the action of FMDP-dipeptides provided evidence demonstrating that the lack of endogenous GICN-6-P could be a reason for the triggering of bacterial autolysis. Peptides containing the inhibitors of GICN-6-P isomerase are one of the very few antimicrobial agents known that exhibit both bactericidal and fungicidal effects.
\end{abstract}

Keywords: dipeptides, Bacillus subtilis, cell wall

\section{INTRODUCTION}

The enzymes participating in the biosynthesis of peptidoglycan have long been considered attractive targets for antibacterial agents. Most of the known, established 'cell-wall-acting' agents interfere in the biosynthesis, assembly and cross-linking of the peptide part of bacterial peptidoglycan. Among them the most notable examples are the $\beta$-lactam antibiotics and glycopeptides such as vancomycin and teicoplanin. The presence of non-protein amino acids, including D-amino acids and meso-2,6-diaminopimelic acid (meso-DAP) in the peptidoglycan structure, has pointed to the enzymes in-

\section{tDeceased.}

Abbreviations: FMDP, $N^{3}$-(4-methoxyfumaroyl)-L-2,3-diaminopropanoic acid; Fru-6-P, D-fructose 6-phosphate; GICNAC, N-acetyl-D-glucosamine; GIcN-6-P, D-glucosamine 6-phosphate; DAP, 2,6-diaminopimelic acid; Nva, L-norvaline; UDP-MurNAC-tripeptide, UDP- $N$-acetylmuramyl-L-Ala- $\gamma$-D-Glumeso-DAP; UDP-MurNAC-pentapeptide, UDP-N-acetylmuramyl-L-Ala- $\gamma$-DGlu-meso-DAP-D-Ala-D-Ala. volved in their formation as potential targets. Indeed, several alanine analogues, such as $\beta$-haloalanines (Boisvert et al., 1986), L-aminoethylphosphonic acid (Atherton et al., 1979), L-aminomethylphosphonic acid (Atherton $e$ al., 1982), $\beta$-chloro- $\alpha$-aminoethylphosphonic acid (Vo-Quang et al., 1986) and D-cycloserine (Neuhaus \& Hammes, 1981) were found to inhibit alanine racemase, D-Ala:D-Ala ligase and D-amino acid transaminase. Some interesting inhibitors of various enzymes of the meso-DAP biosynthetic pathway have also been proposed (Girodeau et al., 1986; Berges et al., 1986; Bauman et al., 1988). On the other hand, very few compounds interfering in the biosynthesis of the (GlcNAcMurNAc) ${ }_{n}$ core are known. The antibiotic fosfomycin inhibits phosphoenolpyruvate:UDP-GlcNAc-3-enolpyruvyl transferase (Kahan et al., 1974).

The biosynthetic pathway leading to eventual formation of the amino sugar core of bacterial peptidoglycan is initiated with formation of D-glucosamine 6-phosphate (GlcN-6-P) (Warren, 1972) upon the action of Lglutamine:D-fructose-6-phosphate aminotransferase 
(hexose-isomerizing) (EC 2.6.1.16) known under the trivial name GlcN-6-P isomerase. This enzyme was previously reported to be inhibited by a number of glutamine analogues such as 6-diazo-5-oxo-L-norleucine, azaserine, albizziin and anticapsin (Chmara et al., 1986; Badet et al., 1987). Unfortunately, these inhibitors are not selective and can interact with some other enzymes utilizing L-glutamine as a substrate. On the other hand, a rationally designed glutamine analogue, $N^{3}$-(4-methoxyfumaroyl)-L-2,3-diaminopropanoic acid (FMDP), appears to be a strong and selective inhibitor of GlcN-6-P isomerase from prokaryotic (Chmara et al., 1986, Andruszkiewicz et al., 1986) and eukaryotic organisms (Milewski et al., 1985). FMDP inactivates the enzyme, forming a covalent bond with the Cys- 1 residue localized in the glutamine-binding domain (Kucharczyk et al., 1990). Although FMDP itself is poorly transported into microbial cells and thus not able to inhibit microbial growth at low concentrations, incorporation of this compound into an oligopeptide structure, according to the 'warhead delivery' concept, has afforded a series of FMDP-oligopeptides exhibiting high antimicrobial activity, especially against humanpathogenic fungi and Gram-positive bacteria (Andruszkiewicz et al., 1987, 1990).

In this paper we present the results of our studies on the factors limiting the growth-inhibitory activity and physiological consequences of the action of FMDPdipeptides against Bacillus subtilis.

\section{METHODS}

Growth media. The following media were used. TSB, Tryptic Soy Broth (Difco). MBD, Minimal Broth Davis (Difco) supplemented with $0 \cdot 1 \%$ each of glucose, Yeast Extract (Difco) and Casamino acids (Difco). MAD, MBD medium supplemented with $1.5 \%$ (w/v) Bacto Agar (Difco). CGPY, a rich growth medium containing $\left(\mathrm{g} \mathrm{l}^{-1}\right): \mathrm{Na}_{2} \mathrm{HPO}_{4}, 6 ; \mathrm{NaCl}, 3$; $\mathrm{NH}_{4} \mathrm{Cl}, 2 ; \mathrm{MgCl}_{2} .6 \mathrm{H}_{2} \mathrm{O}, 0 \cdot 1 ; \mathrm{Na}_{2} \mathrm{SO}_{4}, 0 \cdot 15 ; \mathrm{KH}_{2} \mathrm{PO}_{4}, 3$; Bacto Peptone (Difco), 10; Yeast Extract, $0 \cdot 1 ; \mathrm{pH} 7 \cdot 0$. CWSM, a cell wall synthesis medium containing $\left(\mathrm{g} \mathrm{l}^{-1}\right): \mathrm{KH}_{2} \mathrm{PO}_{4}, 6$; $\mathrm{K}_{2} \mathrm{HPO}_{4}, 6 ; \mathrm{NH}_{4} \mathrm{Cl}, 2 ; \mathrm{MgSO}_{4} .7 \mathrm{H}_{2} \mathrm{O}, 0.05 ; \mathrm{FeSO}_{4}, 0.005$; glucose, 2; uracil, 0.04 ; L-alanine, 0.005 ; L-glutamic acid, 0.12 ; meso-DAP, 0.05; Casamino acids, 1 ; Yeast Extract, 1; pH 7.0.

Micro-organism. Bacillus subtilis ATCC 6633 was used throughout the study. The cells were stored on MAD slants and transferred monthly.

Chemicals. FMDP and FMDP-peptides were synthesized in our laboratory, as described previously (Andruszkiewicz et al., 1987). L- $\left[2,3-{ }^{3} \mathrm{H}\right]$ Alanine (sp. act. $2220 \mathrm{GBq} \mathrm{mmol}^{-1}$ ), $\left[5,6-{ }^{3} \mathrm{H}\right]$ uridine (sp. act. $1295 \mathrm{GBq} \mathrm{mmol}^{-1}$ ) and $\left[\mathrm{U}^{14} \mathrm{C}\right]$ UDP-GlcNAc (sp. act. $7 \cdot 4 \mathrm{GBq} \mathrm{mmol}^{-1}$ ) were from Amersham. DL- $\left[1-{ }^{14} \mathrm{C}\right]$ Alanine (sp. act. $410 \mathrm{MBq} \mathrm{mmol}^{-1}$ ) was from the Institute of Nuclear Research, Ŝwierk, Poland. Penicillin G, vancomycin, D-cycloserine and 6-diazo-5-oxo-Lnorleucine were from Sigma. Cloxacillin and flucloxacillin were from Beecham. All other chemicals were from Serva.

Estimation of antibacterial activity. MIC was determined by a serial dilution method in liquid MBD medium. Tubes containing serially diluted L-norvalyl-FMDP (Nva-FMDP) and control tubes, without the antibacterial agent, were inoculated with $5 \times 10^{6}$ c.f.u. $\mathrm{ml}^{-1}$ of an overnight culture of B. subtilis in
MBD and then incubated for $18 \mathrm{~h}$ at $37^{\circ} \mathrm{C}$. MIC was defined as the lowest drug concentration preventing visible growth.

Disc diffusion assay. MAD medium (1 litre) was inoculated with $1 \mathrm{ml}$ of the $B$. subtilis culture grown in TSB medium for $6 \mathrm{~h}$ at $37^{\circ} \mathrm{C}$. Aliquots $(15 \mathrm{ml})$ of the seeded agar medium were poured into $100 \mathrm{~mm}$ Petri dishes. The FMDP-peptides were dissolved in $25 \mathrm{mM}$ potassium phosphate buffer, $\mathrm{pH} 7 \cdot 2$, and the solutions were sterilized by filtration through $0.22 \mu \mathrm{m}$ Millipore membrane filters. FMDP-peptide solutions $(10 \mu \mathrm{l}$, containing $50 \mathrm{mmol}$ FMDP-dipeptide) were adsorbed onto $13 \mathrm{~mm}$ Schleicher \& Schuell discs and the discs were placed on the seeded agar surface in Petri dishes. For antagonism studies, discs saturated with solutions of different oligopeptides were co-applied with those containing FMDP-peptides. Plates were incubated at $37^{\circ} \mathrm{C}$ for $18 \mathrm{~h}$ and growth inhibition zones were measured.

Uptake of peptides. B. subtilis cells, grown exponentially in MBD medium at $37^{\circ} \mathrm{C}$ were harvested, washed with saline and resuspended in $50 \mathrm{mM}$ potassium phosphate buffer, $\mathrm{pH} 7 \cdot 0$, containing $0.2 \%$ glucose to the final cell density corresponding to $0.3 \mathrm{mg}$ dry wt cells $\mathrm{ml}^{-1}$. Cell suspensions were preincubated at $37^{\circ} \mathrm{C}$ for $10 \mathrm{~min}$ and peptides, previously dissolved in minimal aliquots of potassium phosphate buffer, were added to a final concentration of $100 \mu \mathrm{M}$. At that moment and at $10 \mathrm{~s}$ intervals, $2 \mathrm{ml}$ samples of the cell suspension were withdrawn and filtered immediately through Whatman GF/C glass fibre filters under suction. Mixtures containing bacterial cells in phosphate buffer/glucose and $100 \mu \mathrm{M}$ peptide in phosphate buffer/glucose were processed as negative and positive controls, respectively. Samples of the filtrate aliquots $(1 \mathrm{ml})$ were taken for assay. The concentration of an oligopeptide remaining in filtrates was assayed by the colorimetric TNBS method (Milewski et al., 1988).

Cleavage of dipeptides in cell-free extracts. $B$. subtilis cells grown overnight in $\mathrm{MBD}$ medium at $37^{\circ} \mathrm{C}$ were harvested and washed with ice-cold saline. Wet cells were resuspended in small aliquots of $50 \mathrm{mM}$ potassium phosphate buffer, $\mathrm{pH} 7 \cdot 0$, and subjected to ultrasonic disruption with a Branson sonifier. Cell wall debris was removed by centrifugation $(15000 \mathrm{~g}$, $\left.4^{\circ} \mathrm{C}, 20 \mathrm{~min}\right)$. Mixtures containing $100 \mu \mathrm{M}$ dipeptide and the cell-free extract $\left(1 \mathrm{mg}\right.$ protein $\left.\mathrm{ml}^{-1}\right)$ in $50 \mathrm{mM}$ potassium phosphate buffer, $\mathrm{pH} 7.0$, were incubated at $37^{\circ} \mathrm{C}$. At zero time and at 10 min intervals, $0.5 \mathrm{ml}$ samples of the incubation mixtures were withdrawn and taken for determination of free amino acids, using the Cd-ninhydrin method of Doi et al. (1981). In each case the results were corrected for a background level of free amino acids present in a control mixture containing the cell-free extract in phosphate buffer.

Purification of GlcN-6-P isomerase. Unless otherwise stated, all operations were performed at $4^{\circ} \mathrm{C}$. Buffers used were: buffer A, $25 \mathrm{mM}$ potassium phosphate buffer, $\mathrm{pH} 7 \cdot 5,1 \mathrm{mM}$ EGTA, $1 \mathrm{mM} \mathrm{KCl}, 1 \mathrm{mM}$ DTT; buffer B, buffer A supplemented with $10 \mathrm{mM}$ L-glutamine, $0.5 \mathrm{mM}$ D-glucose 6-phosphate and $500 \mathrm{mM}$ sucrose; buffer C, buffer A supplemented with $15 \mathrm{mM}$ D-fructose 6-phosphate (Fru-6-P) and $500 \mathrm{mM}$ sucrose. $B$. subtilis cells grown overnight in TSB medium at $37^{\circ} \mathrm{C}$ were harvested, washed twice with ice-cold buffer $\mathrm{A}$ and resuspended in a small volume of buffer $B$. The dense cell suspension was subjected to sonic disruption with a Branson sonifier. The cell debris were removed by centrifugation $(55000 \mathrm{~g}, 90 \mathrm{~min})$. The supernatant (crude extract) was treated dropwise with a one-third volume of a $2 \%(v / v)$ solution of polymyxin sulfate in buffer $\mathrm{B}$. The resulting suspension was centrifuged and the precipitate was discarded. The supernatant was diluted threefold with buffer B and applied to a 
Cellex D column, equilibrated previously with buffer B. The column was washed with $100 \mathrm{ml}$ buffer B and proteins were eluted with a $0-0.3 \mathrm{M} \mathrm{KCl}$ gradient in buffer B. Fractions containing GlcN-6-P isomerase activity were combined, diluted fourfold with buffer $C$ and applied to a DEAE-Sepharose CL-6B column, previously equilibrated with buffer C. The column was washed with buffer $C$ and then eluted with a $0-0.3 \mathrm{M} \mathrm{KCl}$ gradient in buffer C. Fractions containing GlcN6-P isomerase activity were pooled. The partially purified enzyme exhibited a specific activity of $0.43 \mu \mathrm{mol}$ GlcN-6-P formed $\min ^{-1}$ (mg protein) $)^{-1}$ and constituted $11 \%$ of protein present in the final preparation after the DEAE-Sepharose CL$6 \mathrm{~B}$ column, as judged from densitometric SDS-PAGE analysis (not shown). The purity of this preparation was sufficient for kinetic studies since it was free from glutaminase and phosphoglucose isomerase activities. The enzyme stored in buffer $\mathrm{C}$ at $4^{\circ} \mathrm{C}$ was relatively stable for $2-4$ weeks.

Determination of GICN-6-P isomerase activity. The standard incubation mixture contained $15 \mathrm{mM}$ Fru-6-P, $5 \mathrm{mM} \mathrm{L-}$ glutamine, $1 \mathrm{mM}$ DTT, $1 \mathrm{mM}$ EGTA and appropriately diluted enzyme in $25 \mathrm{mM}$ potassium phosphate buffer, $\mathrm{pH} 7 \cdot 5$. In kinetic experiments the concentration of one of the enzyme substrates was fixed and that of the other one was changed. Inhibitors were added if necessary. Samples were incubated at $37^{\circ} \mathrm{C}$ for $30 \mathrm{~min}$. The enzymic reaction was started by the addition of enzyme and was terminated by boiling for $1 \mathrm{~min}$. The concentration of GlcN-6-P formed was determined by a modified Elson-Morgan procedure (Kenig et al., 1976). One unit of enzyme activity is defined as the amount of enzyme catalysing the formation of $1 \mu \mathrm{mol} \mathrm{GlcN}-6-\mathrm{P} \mathrm{min}^{-1}$.

Inactivation of GICN-6-P isomerase in vitro. Progress of timeand concentration-dependent inactivation of GlcN-6-P isomerase by FMDP was followed using the previously described method (Chmara et al., 1986) applying a small columncentrifuge procedure of Penefsky (1977) for separation of the enzyme from the unbound inactivator.

Inactivation of GlcN-6-P isomerase in vivo. $B$. subtilis cells grown overnight in MBD medium were harvested, washed and resuspended in prewarmed fresh MBD medium to an $\mathrm{OD}_{660}$ of 0.5 . After $30 \mathrm{~min}$ preincubation at $37^{\circ} \mathrm{C}$ with shaking, inhibitors were added at appropriate concentrations. Incubation was continued for another $60 \mathrm{~min}$. Samples of the cell cultures were rapidly cooled at time intervals, cells were harvested, washed with buffer $A$ and resuspended in small volumes of ice-cold buffer B. Cells were disrupted by sonication, cell debris separated by centrifugation $\left(10000 \mathrm{~g}, 4^{\circ} \mathrm{C}\right.$, $10 \mathrm{~min}$ ) and the crude extracts were passed through small Sephadex G-25 columns, equilibrated previously with buffer B. GlcN-6-P isomerase activity in protein-containing eluates was determined as described above.

Isolation of radioactively labelled cell wall precursors. $B$. subtilis cells grown exponentially in CGPY medium were washed and resuspended in CWSM medium containing $100 \mu \mathrm{g}$ chloramphenicol ml $\mathrm{m}^{-1}$ to the cell density of $5 \times 10^{8}$ cells $\mathrm{ml}^{-1}$. After $15 \mathrm{~min}$ preincubation at $37^{\circ} \mathrm{C}, 148 \mathrm{kBq}\left[5,6-{ }^{3} \mathrm{H}\right]$ uridine $\mathrm{ml}^{-1}$ and an inhibitor at appropriate concentration were added. Incorporation was carried out for $30 \mathrm{~min}$ at $37^{\circ} \mathrm{C}$. The cells were harvested and the pellet was resuspended in a small volume of distilled water and heated for $15 \mathrm{~min}$ in a boiling water bath. After chilling in ice-cold water, cold $40 \%$ (w/v) TCA was added to the final concentration of $5 \%$. The suspension was centrifuged, the pellet was discarded and $15 \mathrm{mg}$ charcoal (ml supernatant) ${ }^{-1}$ was added. The suspension was gently shaken for $30 \mathrm{~min}$ and then pipetted into a small column ( $7 \mathrm{~mm}$ diam.). The non-adsorbed material was removed by five washings with $3 \mathrm{ml}$ aliquots of distilled water.
The adsorbed material was eluted by four washings with $1 \mathrm{ml}$ aliquots of ethanol/0.1 M ammonia $(1: 1, \mathrm{v} / \mathrm{v})$ and these washings were combined. The solvent was removed under reduced pressure and the residue containing labelled cell wall precursors was dissolved in a small but defined volume of distilled water.

Cell wall precursors containing labelled uridine were separated by two-dimensional paper chromatography to avoid the possibility of interference with other uridine derivatives, such as UDP and UTP. Paper chromatography was performed on Whatman $3 \mathrm{MM}$ paper. Aliquots containing labelled precursors were applied as small spots at the corner and the chromatograms were first developed with ethanol/1 $\mathrm{M}$ ammonium acetate, $\mathrm{pH} 7 \cdot 5(7: 3, \mathrm{v} / \mathrm{v})$ and then in the second dimension with isobutyric acid/1 $\mathrm{M}$ ammonia $(5: 3, \mathrm{v} / \mathrm{v})$. The chromatograms were air-dried and cut into $2 \times 2 \mathrm{~cm}$ squares which were counted for radioactivity.

Nucleotides were identified by comparing their location with appropriate standard precursors labelled with L- $\left[{ }^{3} \mathrm{H}\right]$ alanine, isolated and purified as described by Lugtenberg et al. (1972), or with commercially available [U- ${ }^{14}$ C]UDP-GlcNAc. The bound $N$-acetylhexosamine content was determined by the Elson-Morgan reaction, according to the procedure of Ward (1975).

Estimation of the peptidoglycan synthesis rate. $B$. subtilis cells grown overnight in CGPY medium at $37^{\circ} \mathrm{C}$ were harvested, washed and resuspended in prewarmed CWSM medium. Growth was performed at $37^{\circ} \mathrm{C}$ with vigorous shaking until $\mathrm{OD}_{660}$ reached $0 \cdot 5-0 \cdot 6$. Chloramphenicol was added to a final concentration of $100 \mu \mathrm{g} \mathrm{ml}^{-1}$ and incubation was continued. After $15 \mathrm{~min}, 19 \mathrm{kBq} \mathrm{DL}-\left[1{ }^{14} \mathrm{C}\right]$ alanine $\mathrm{ml}^{-1}$ and an inhibitor at appropriate concentration were added. Samples of the cell suspension $(0.5 \mathrm{ml})$ were withdrawn and combined with $5 \mathrm{ml}$ ice-cold $10 \%$ TCA. The mixtures were kept on ice for at least $15 \mathrm{~min}$ and then heated at $80^{\circ} \mathrm{C}$ for $15 \mathrm{~min}$ to remove teichoic acids. Precipitates were separated by filtration through Whatman GF/C glass fibre filters, washed with ice-cold $10 \%$ TCA, ice-cold water and ethanol, air-dried and counted for radioactivity.

Bacteriolytic effect. B. subtilis cells grown exponentially in CGPY medium at $37^{\circ} \mathrm{C}$ were washed and resuspended in prewarmed MBD medium to an $\mathrm{OD}_{660}$ of $0 \cdot 15$. Cell suspensions were incubated at $37^{\circ} \mathrm{C}$ with vigorous shaking. Inhibitors at appropriate concentrations were added after 15 min preincubation and the growth rate was followed by measurement of $\mathrm{OD}_{660}$. Samples of the cell suspensions were collected at time intervals and taken for inspection by scanning electron microscopy.

Scanning electron microscopy. Microbial cells were harvested centrifugation at $2000 \mathrm{~g}$ for $5 \mathrm{~min}$, washed four times with sterile saline, fixed for $12 \mathrm{~h}$ in $0.25 \%$ glutaraldehyde, washed four times and resuspended in $5 \mathrm{ml}$ sterile demineralized water. A drop of each suspension was air-dried on $10 \times 10 \mathrm{~mm}$ glass slides. The slides were attached to specimen stubs, coated with pure gold in a high-vacuum SEM coating unit and observed in a Stereo Scan 200 Cambridge electron microscope at $30 \mathrm{kV}$.

Other methods. General peptidase activity was determined by TNBS/ $\mathrm{Cu}^{2+}$ described by Payne (1972). Protein concentration was measured using the method of Bradford (1976). SDSPAGE was performed using the discontinuous method of Laemmli (1970). Radioactivity was measured in a Beckman LS 3801 scintillation counter. Spectrophotometric measurements were made in a Perkin Elmer Lambda Bio UV/Visible spectrometer. 


\section{RESULTS AND DISCUSSION}

\section{Transport, cleavage and antimicrobial activity of FMDP-dipeptides}

Several FMDP-containing dipeptides were examined to determine factors affecting their in vitro activity against B. subtilis. All the compounds inhibited bacterial growth but data presented in Table 1 clearly demonstrate that their antibacterial potency was strongly dependent on the primary dipeptide sequence. Generally, X-FMDP dipeptides were more active than their FMDP-X counterparts. The most active compound, namely NvaFMDP, exhibited an MIC of $1.6 \mu \mathrm{g} \mathrm{m}^{-1}$ in a serial dilution test in liquid MBD medium. No growth inhibition was observed for FMDP alone. This compound was not transported into $B$. subtilis cells, thus confirming an opinion suggesting the strict specificity of amino acid permeases (Anraku, 1980). On the contrary, FMDP-dipeptides were rapidly taken up by the bacteria with initial velocities quite comparable to those of some model dipeptides composed of protein amino acids. Actually, the uptake was so rapid that after a $30-40 \mathrm{~s}$ period of linear progress, a substantial slowing down was observed, obviously due to the substantially decreased dipeptide concentration in the medium. Uptake rates shown in Table 1 were therefore calculated from the data measured for the initial $30 \mathrm{~s}$ period and thus reflect the true initial velocities. Such high velocities of uptake of FMDP-dipeptides must mean that transport into cells is unlikely to be a factor determining the antibacterial activity of these compounds, despite differences in the uptake rate dependent on dipeptide constitution. On the other hand, cleavage of the dipeptides by peptidases present in the crude extract prepared from B. subtilis cells was about two orders of magnitude slower than their uptake. As is shown in Table 1, especially low rates were observed for FMDP$\mathrm{X}$ dipeptides. Therefore, one may assume that the velocity of releasing of the active 'warhead' inside the cells upon the action of intracellular peptidases is a factor limiting the antibacterial activity of FMDPdipeptides, although FMDP-Ala, FMDP-Nva and FMDP-Leu do not seem to follow this rule. This situation is different from that found previously for

Table 1. Growth-inhibitory activity, uptake and cleavage rates of FMDP-peptides by B. subtilis

\begin{tabular}{|lccc|}
\hline FMDP-peptide & $\begin{array}{c}\text { Inhibition zone } \\
\text { diameter }(\mathbf{m m})^{*}\end{array}$ & $\begin{array}{c}\text { Uptake rate } \pm \text { SD [nmol } \\
\left.\text { min }^{-1}(\mathbf{m g} \text { dry wt })^{-1}\right] \dagger\end{array}$ & $\begin{array}{c}\text { Cleavage rate } \pm \text { SD [nmol } \\
\left.\text { min }^{-1} \text { (mg protein }\right)^{-1} \text { ] }\end{array}$ \\
\hline Gly-FMDP & 21 & $40 \pm 8$ & $1 \cdot 8 \pm 0 \cdot 25$ \\
Ala-FMDP & 31 & $175 \pm 15$ & $3 \cdot 7 \pm 0 \cdot 15$ \\
Val-FMDP & 31 & $200 \pm 18$ & $5 \cdot 2 \pm 0 \cdot 2$ \\
Leu-FMDP & 30 & $185 \pm 13$ & $4 \cdot 6 \pm 0 \cdot 25$ \\
Nva-FMDP & 32 & $190 \pm 8$ & $5 \cdot 6 \pm 0 \cdot 25$ \\
Met-FMDP & 30 & $162 \pm 10$ & $5 \cdot 1 \pm 0 \cdot 3$ \\
Phe-FMDP & 25 & $124 \pm 7$ & $3 \cdot 2 \pm 0 \cdot 15$ \\
Tyr-FMDP & 23 & $135 \pm 9$ & $3 \cdot 8 \pm 0 \cdot 25$ \\
Lys-FMDP & 15 & $40 \pm 9$ & $0 \cdot 1 \pm 0 \cdot 2$ \\
FMDP-Gly & 16 & $68 \pm 6$ & $0 \cdot 2 \pm 0 \cdot 1$ \\
FMDP-Ala & 25 & $103 \pm 14$ & $0 \cdot 8 \pm 0 \cdot 15$ \\
FMDP-Val & 21 & $86 \pm 8$ & $0 \cdot 9 \pm 0 \cdot 15$ \\
FMDP-Leu & 25 & $105 \pm 10$ & $0 \cdot 8 \pm 0 \cdot 2$ \\
FMDP-Nva & 26 & $102 \pm 7$ & $0 \cdot 7 \pm 0 \cdot 15$ \\
FMDP-Met & 18 & $122 \pm 5$ & $0 \cdot 4 \pm 0 \cdot 1$ \\
FMDP-Phe & 19 & $88 \pm 8$ & $0 \cdot 35 \pm 0 \cdot 05$ \\
FMDP-Tyr & 20 & $96 \pm 9$ & $0 \cdot 45 \pm 0 \cdot 05$ \\
FMDP & No zone & Not detected & - \\
\hline
\end{tabular}

* Growth-inhibitory activity was determined by a disc diffusion assay on MAD agar inoculated with an exponentially growing culture $\left(5 \times 10^{6}\right.$ c.f.u. $\left.\mathrm{ml}^{-1}\right)$ of B. subtilis. Discs contained $50 \mathrm{nmol}$ of an FMDPdipeptide. Petri dishes were incubated for $18 \mathrm{~h}$ at $37^{\circ} \mathrm{C}$ and inhibition zones were measured to an accuracy of $\pm 1 \mathrm{~mm}$.

† Samples of B. subtilis cell suspensions incubated at $37^{\circ} \mathrm{C}$ in $50 \mathrm{mM}$ potassium phosphate buffer, $\mathrm{pH} 7.0$, containing $0.2 \%$ glucose and $100 \mu \mathrm{M}$ dipeptide were withdrawn at $10 \mathrm{~s}$ intervals and immediately filtered. The concentration of the dipeptide remaining in the filtrate was estimated by the TNBS procedure.

$\ddagger$ Mixtures containing $100 \mu \mathrm{M}$ dipeptide and cell-free extract prepared from $B$. subtilis cells $(1 \mathrm{mg}$ protein $\mathrm{ml}^{-1}$ ) in $50 \mathrm{mM}$ potassium phosphate buffer, $\mathrm{pH} 7.0$, were incubated at $37^{\circ} \mathrm{C}$. At zero time and at $10 \mathrm{~min}$ intervals, samples of the incubation mixtures were withdrawn and taken for the determination of free amino acids. 


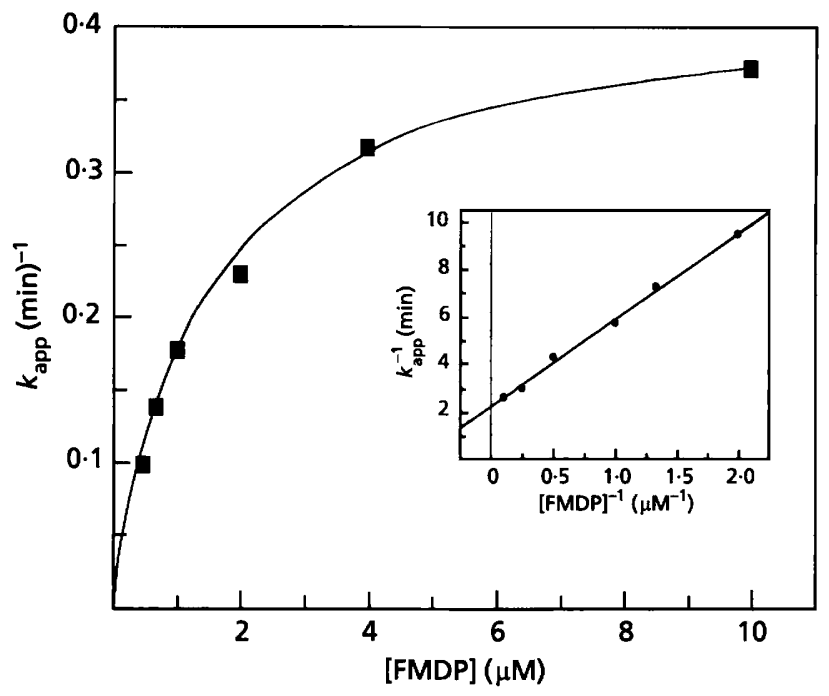

Fig. 1. Dependence of the pseudo-first order rate constants of GICN-6-P isomerase inactivation on FMDP concentration. Inset: a double reciprocal plot of the data according to Dixon \& Webb (1979).

Candida albicans cells, where the low transport rates strongly affected the anticandidal activity of FMDPdipeptides (Milewski et al., 1991).

A disc diffusion experiment was performed to identify a permease transporting the FMDP-dipeptides into $B$. subtilis cells. The diameter of the growth inhibition zone [ $32 \mathrm{~mm}$ found for the action of Nva-FMDP $(50 \mathrm{nmol}$ per disc)] was reduced to $21-24 \mathrm{~mm}$ when any of the dipeptides L-Leu-L-Ala, L-Ala-L-Ala and L-Met-L-Val or tripeptides L-Ala-L-Ala-L-Ala and L-Gly-L-Leu-L-Tyr in 500-fold molar excess was co-applied with the FMDPdipeptide. No decrease of the growth inhibition zone was observed for the co-applied dipeptide D-Ala-D-Ala and a tetrapeptide (L-Ala) ${ }_{4}$. Similar results were obtained for other FMDP-peptides, thus indicating that these compounds are transported into $B$. subtilis cells by a stereospecific peptide permease. The multiplicity of the oligopeptide transport systems in Escherichia coli and C. albicans is well documented (Payne, 1980; McCarthy et al., 1985; Milewski et al., 1988). Gram-positive bacteria have not been extensively studied in this respect; however, the presence of an oligopeptide permease and a di-tripeptide permease in $B$. subtilis has been reported (Perego et al., 1991; Mathiopoulos et al., 1991). Since we found that the tetrapeptide (L-Ala) ${ }_{4}$, unable to compete with Nva-FMDP in the disc diffusion test, was actually transported to $B$. subtilis cells at a rate of $70 \mathrm{nmol} \mathrm{min}{ }^{-1}(\mathrm{mg} \mathrm{dry} \mathrm{wt})^{-1}$, it seems very likely that the uptake of $(\mathrm{Ala})_{4}$ is mediated by the oligopeptide permease and that of FMDP-dipeptides by the ditripeptide permease.

Cleavage of FMDP-dipeptides by peptidases present in the crude extract was inhibited by $50 \%$ in the presence of $12 \mathrm{mM}$ EDTA, but its velocity nearly doubled in the presence of $1 \mathrm{mM} \mathrm{MnCl}$ or $\mathrm{CoCl}_{2}$. When we separated the components of the $B$. subtilis crude extract on the DEAE-cellulose column, eluted with a linear $0-0.5 \mathrm{M}$ $\mathrm{KCl}$ gradient, three peaks showing $\mathrm{Mn}^{2+} / \mathrm{Co}^{2+}$-dependent dipeptidase activity, as determined using the method of Payne (1972), were found (details not shown). Two activities eluted at lower ionic strength were able to cleave FMDP-dipeptides and several dipeptides composed of protein amino acids. The third activity, eluted at a higher $\mathrm{KCl}$ concentration was specific for Gly-X dipeptides, including Gly-FMDP. These results confirm the multiplicity of intracellular dipeptidases in B. subtilis demonstrated by Desmond et al. (1975).

\section{Interaction of the inhibitor with an intracellular target}

With regard to GlcN-6-P isomerase of different origin, FMDP was previously found to be a stronger inhibitor than its structural analogue, present as the C-terminal amino acid of a dipeptide antibiotic A19009 (Chmara et al., 1986). The partially purified GlcN-6-P isomerase from $B$. subtilis was also inhibited by this amino acid. Kinetic analysis of this process revealed that the inhibition was competitive with regard to L-glutamine $\left(K_{\mathrm{i}}=4 \times 10^{-7} \mathrm{M}\right)$ and uncompetitive with regard to Fru-6-P (graphs not shown). The low $K_{1} / K_{\mathrm{M}}$ ratio $\left(1.25 \times 10^{-3}\right)$ reflects the high affinity of FMDP to the Lglutamine binding site of the enzyme and an uncompetitive mode of inhibition in respect of Fru-6-P indicates that the inhibitor binds predominantly to the [enzyme: Fru-6-P] complex.

Incubation of $B$. pumilus GlcN-6-P isomerase with FMDP at different concentrations, in the absence of $\mathrm{L}-$ glutamine, caused time- and concentration-dependent inactivation of the enzyme. When the natural logarithm of enzyme residual activity, determined after separation of the enzyme protein from an excess of unbound inhibitor by enforced gel filtration, was plotted versus

Table 2. Inactivation of GICN-6-P isomerase in B. subtilis cells by FMDP-peptides in vivo

Exponentially growing $B$. subtilis cells were treated with FMDP-dipeptides. At time intervals sample cells were harvested, washed and broken. Cell-free extracts were passed through small Sephadex G-25 columns and GlcN-6-P isomerase activity was determined in eluates. The enzyme activity in cellfree extracts prepared from control cells (not treated with FMDP-dipeptides) was practically constant for $60 \mathrm{~min}$ at $7 \cdot 2 \pm 0 \cdot 2 \mathrm{nmol} \mathrm{GlcN}-6-\mathrm{P} \mathrm{min}^{-1}$ (mg protein) ${ }^{-1}$.

\begin{tabular}{|lccc|}
\hline Peptide $(\boldsymbol{\mu M})$ & \multicolumn{3}{c|}{$\begin{array}{c}\text { Percentage inhibition } \\
\text { of GlcN-6-P isomerase activity after : }\end{array}$} \\
\cline { 2 - 4 } & $\mathbf{1 0} \mathbf{~ m i n}$ & $\mathbf{3 0} \mathbf{~ m i n}$ & $\mathbf{6 0} \mathbf{m i n}$ \\
\hline Gly-FMDP (2) & 23 & 44 & 62 \\
Nva-FMDP (2) & 52 & 83 & Bacteriolysis \\
Nva-FMDP (10) & 85 & Bacteriolysis & Bacteriolysis \\
FMDP-Ala (2) & 15 & 26 & 45 \\
\hline
\end{tabular}


incubation time, a set of straight lines was obtained (not shown). Kinetic analysis of this inactivation, shown in Fig. 1, revealed a hyperbolic dependence of apparent pseudo-first order rate constants, $k_{\mathrm{app}}$, on FMDP concentration. On the other hand, when $k_{\mathrm{app}}{ }^{-1}$ was plotted against the reciprocal of FMDP concentration, a straight line was obtained with a non-zero intercept. This behaviour is consistent with the idea of formation of a reversible [enzyme:inhibitor] complex before irreversible modification of the enzyme, according to the scheme:

$$
\mathrm{E}+\mathrm{I} \underset{k_{-1}}{\stackrel{k_{1}}{\rightleftharpoons}}[\mathrm{E}: \mathrm{I}] \stackrel{k_{2}}{\rightarrow} \mathrm{E}-\mathrm{I}
$$

Steady-state treatment of this process yields the equation (Dixon \& Webb, 1979):

$$
1 / k_{\text {app }}=K_{\mathrm{I}} / k_{2} \times 1 /[\mathrm{I}]+1 / k_{2}
$$

where an inactivation constant, $K_{\mathrm{I}}=k_{-1}+k_{1} / k_{2}$, reflects the affinity of an inactivator to its binding site and $k_{2}$ is the rate constant for the irreversible modification. We found these values to be $K_{\mathrm{I}}=1.42 \times 10^{-6} \mathrm{M}$ and $k_{2}$ $=0.586 \mathrm{~min}^{-1}$. The well-known, commercially available glutamine analogue, 6-diazo-5-oxo-L-norleucine, showed much lower affinity to the $B$. subtilis GlcN-6-P isomerase active site $\left(K_{\mathrm{I}}=75 \mu \mathrm{M}\right)$.

Inactivation of GlcN-6-P isomerase could also be demonstrated under in vivo conditions when suspensions of $B$. subtilis cells were incubated with FMDPdipeptides and the enzyme activity was determined in crude extracts prepared from the harvested cells. Low molecular mass components were removed from the extracts by gel filtration before determination of GlcN6-P isomerase activity. The results of this experiment are summarized in Table 2. Concentrations of FMDPdipeptides used in this experiment were rather low, since

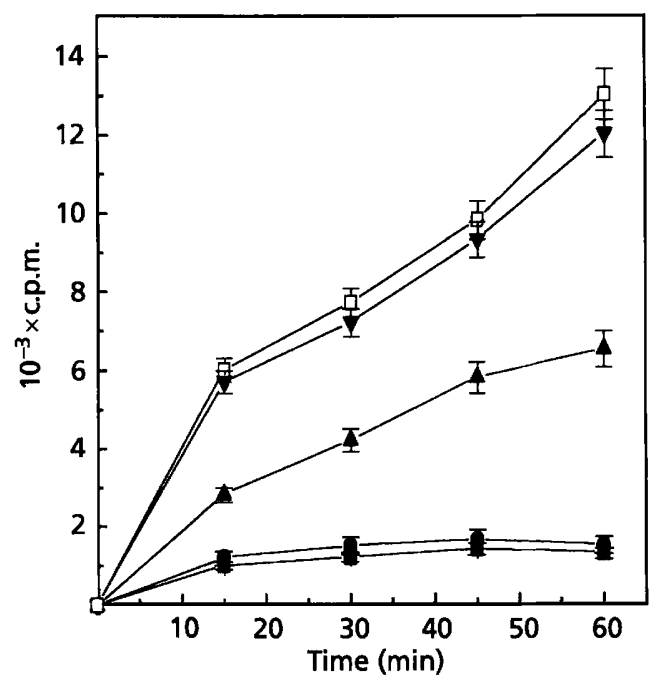

Fig. 2. Influence of Nva-FMDP on incorporation of DL-[1-14C]Ala into peptidoglycan of $B$. subtilis cells. $\square$, Control; $0,1 \mu \mathrm{M}$ Nva-FMDP; $\square, 5 \mu \mathrm{M}$ Nva-FMDP; $\triangle, 1 \mu \mathrm{M}$ Nva-FMDP + $1 \mathrm{mM}$ GICNAC; $\nabla, 1 \mu \mathrm{M}$ Nva-FMDP $+10 \mathrm{mM}$ GlcNAc. Bars indicate SD (three replicates). B. subtilis cells grown exponentially in CWSM medium were treated for $15 \mathrm{~min}$ with $100 \mu \mathrm{g}$ chloramphenicol $\mathrm{ml}^{-1}$ and then labelled with $19 \mathrm{kBq} \mathrm{DL}-\left[1{ }^{-14} \mathrm{C}\right]$ alanine $\mathrm{ml}^{-1}$ in the presence or absence of Nva-FMDP. Samples of the cell suspension $(0.5 \mathrm{ml})$ were withdrawn, treated with ice-cold $10 \%$ TCA for $15 \mathrm{~min}$ and then heated at $80^{\circ} \mathrm{C}$ for $15 \mathrm{~min}$ to remove teichoic acids. Precipitates were separated by filtration through Whatman GF/C glass fibre filters, washed with ice-cold $10 \%$ TCA, ice-cold water and ethanol, air-dried and counted for radioactivity.

at higher concentrations the immediate lysis of bacteria precluded successful harvesting of the cells. Nevertheless, data presented in Table 2 clearly demonstrate that GlcN-6-P isomerase present in B. subtilis cells

Table 3. Accumulation of nucleotide precursors of peptidoglycan in B. subtilis cells treated with Nva-FMDP and other antibiotics

B. subtilis cells suspended in CWSM medium containing $100 \mu \mathrm{g}$ chloramphenicol $\mathrm{ml}^{-1}$ were labelled with $148 \mathrm{kBq}\left[5,6-{ }^{3} \mathrm{H}\right]$ uridine $\mathrm{ml}^{-1}$ for $30 \mathrm{~min}$ at $37^{\circ} \mathrm{C}$ in the presence or absence of cell-wall-acting antibiotics. Then the cells were harvested and broken by consecutive boiling and treatment with $40 \%$ TCA. Labelled nucleotide precursors present in supernatants obtained after removal of cell debris were adsorbed on charcoal and recovered by elution with ethanol/ $0 \cdot 1 \mathrm{M}$ ammonia $(1: 1, \mathrm{v} / \mathrm{v})$ mixture. The bound $\mathrm{N}$-acetylhexosamine content was determined by the Elson-Morgan reaction. Labelled precursors were separated by two-dimensional paper chromatography and nucleotides were identified by comparing their location with appropriate standard precursors. Results presented

\begin{tabular}{|c|c|c|c|c|}
\hline \multirow[t]{2}{*}{ Treatment $\left(\mu \mathrm{g} \mathrm{ml}^{-1}\right)$} & \multirow{2}{*}{ 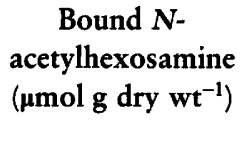 } & \multicolumn{3}{|c|}{ Precursor accumulated (c.p.m. per spot \pm SD) } \\
\hline & & UDP-GlcNAc & $\begin{array}{l}\text { UDP-MurNAc- } \\
\text { tripeptide }\end{array}$ & $\begin{array}{l}\text { UDP-MurNAc- } \\
\text { pentapeptide }\end{array}$ \\
\hline Control & $1 \cdot 8 \pm 0 \cdot 1$ & $368 \pm 30$ & $91 \pm 18$ & $214 \pm 22$ \\
\hline Nva-FMDP (4) & $<0 \cdot 1$ & $18 \pm 11$ & ND & ND \\
\hline D-Cycloserine (4) & $25 \cdot 3 \pm 0 \cdot 3$ & $375 \pm 41$ & $2148 \pm 53$ & $234 \pm 18$ \\
\hline Cloxacillin (4) & $28 \cdot 4 \pm 0 \cdot 3$ & $412 \pm 32$ & $586 \pm 17$ & $2218 \pm 41$ \\
\hline Vancomycin (4) & $39 \cdot 6 \pm 0 \cdot 2$ & $332 \pm 19$ & $348 \pm 43$ & $3865 \pm 120$ \\
\hline
\end{tabular}
in the table are the means of three independent determinations \pm SD. ND, Not detected. 

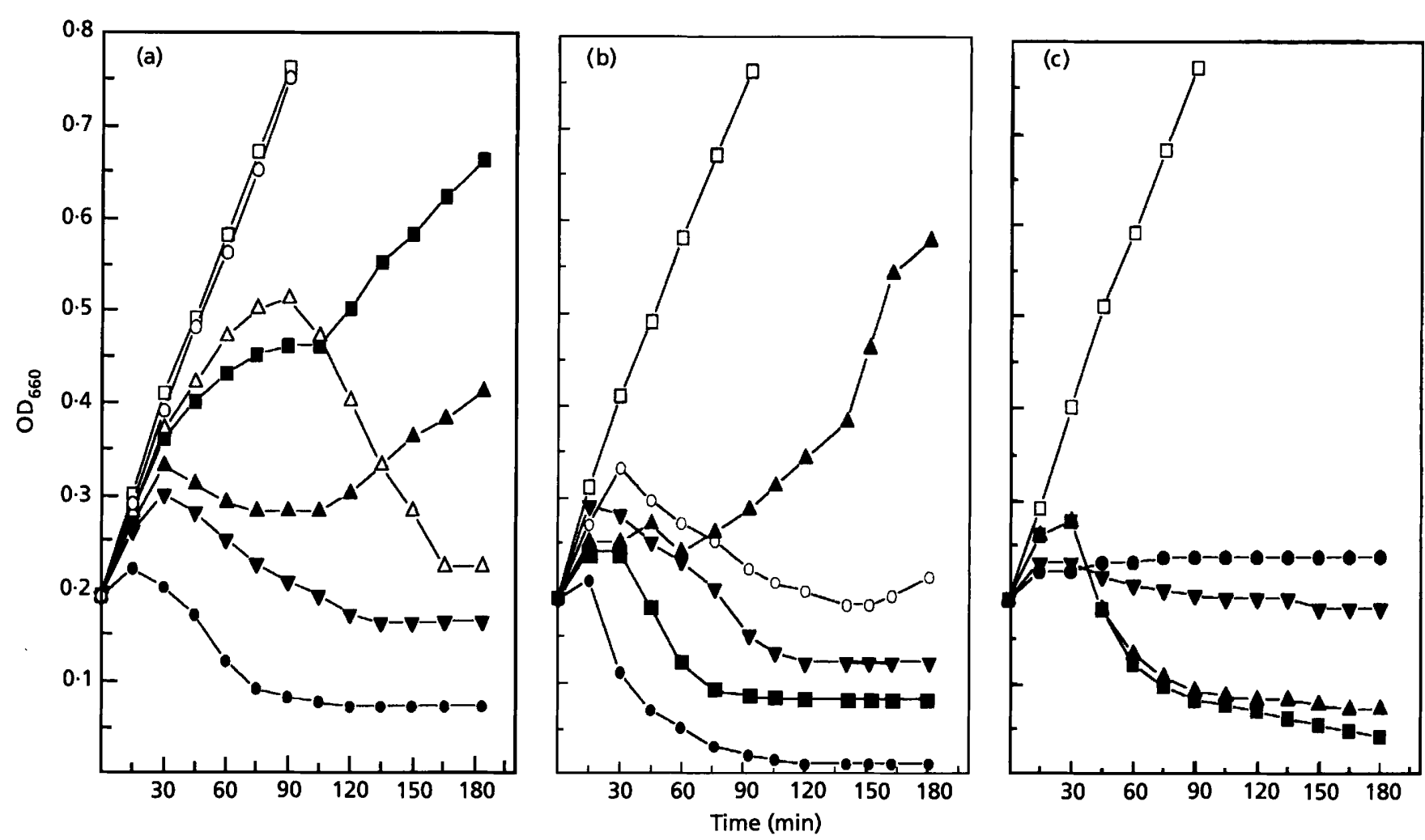

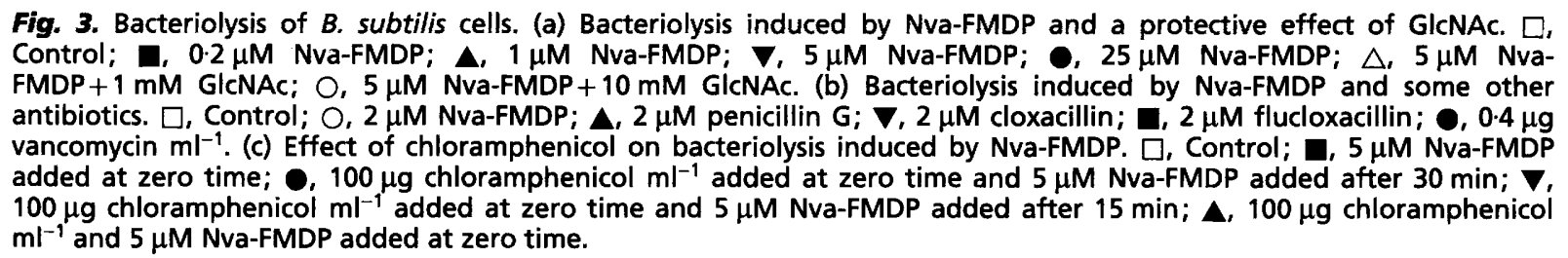

treated with FMDP-dipeptides underwent progressive, irreversible inactivation, since the gel filtration did not restore the original enzyme activity. The progress of this inactivation was much slower for FMDP-Ala. Since these compounds and other FMDP-X dipeptides were shown to be much more slowly hydrolysed by the intracellular peptidases than their structural isomers (Table 1), data presented in Table 2 provide some evidence that only free FMDP can inactivate the $B$. subtilis GlcN-6-P isomerase. This is contrary to the situation found previously for the C. albicans enzyme, where the FMDP-X dipeptides were able to inactivate the enzyme, although the rate of this process was rather low (Milewski et al., 1991). On the other hand, the relatively high antibacterial activity of FMDP-Ala, FMDP-Nva and FMDP-Leu indicates that at least some intact FMDP-peptides can inhibit bacterial GlcN-6-P isomerase.

\section{Physiological consequences of GlcN-6-P isomerase inactivation}

GlcN-6-P isomerase is the first unique enzyme in a biosynthetic pathway leading to eventual formation of
UDP-GlcNAc which, in turn, is a precursor of the main structural component of bacterial peptidoglycan. Therefore, one would expect that FMDP-peptides should strongly affect peptidoglycan biosynthesis.

When B. subtilis cells were treated with $4 \mu \mathrm{g}$ Nva-FMDP $\mathrm{ml}^{-1}$ for $30 \mathrm{~min}$, a dramatic depletion in the intracellular pool of bound $\mathrm{N}$-acetylhexosamines was observed (Table 3). On the other hand, the action of cloxacillin and vancomycin, i.e. antibiotics acting at later stages of the peptidoglycan biosynthetic pathway, induced substantial accumulation of $\mathrm{N}$-acetylhexosamine derivatives. Two-dimensional paper chromatography enabled separation and identification of accumulated, radioactively labelled precursors. UDP-MurNAc-tripeptide (UDP- $N$-acetylmuramyl-L-Ala- $\gamma$-D-Glu-meso-DAP) and UDP-MurNAc-pentapeptide (UDP- $N$-acetylmuramylL-Ala- $\gamma$-D-Glu-meso-DAP-D-Ala-D-Ala) accumulated in cells treated with cloxacillin and vancomycin - antibiotics that interfere in the assembly of bacterial peptidoglycan. The action of $\mathrm{D}$-cycloserine, an inhibitor of alanine racemase, caused accumulation of UDPMurNAc-tripeptide only, but no nucleotide precursors accumulated upon treatment with Nva-FMDP. 

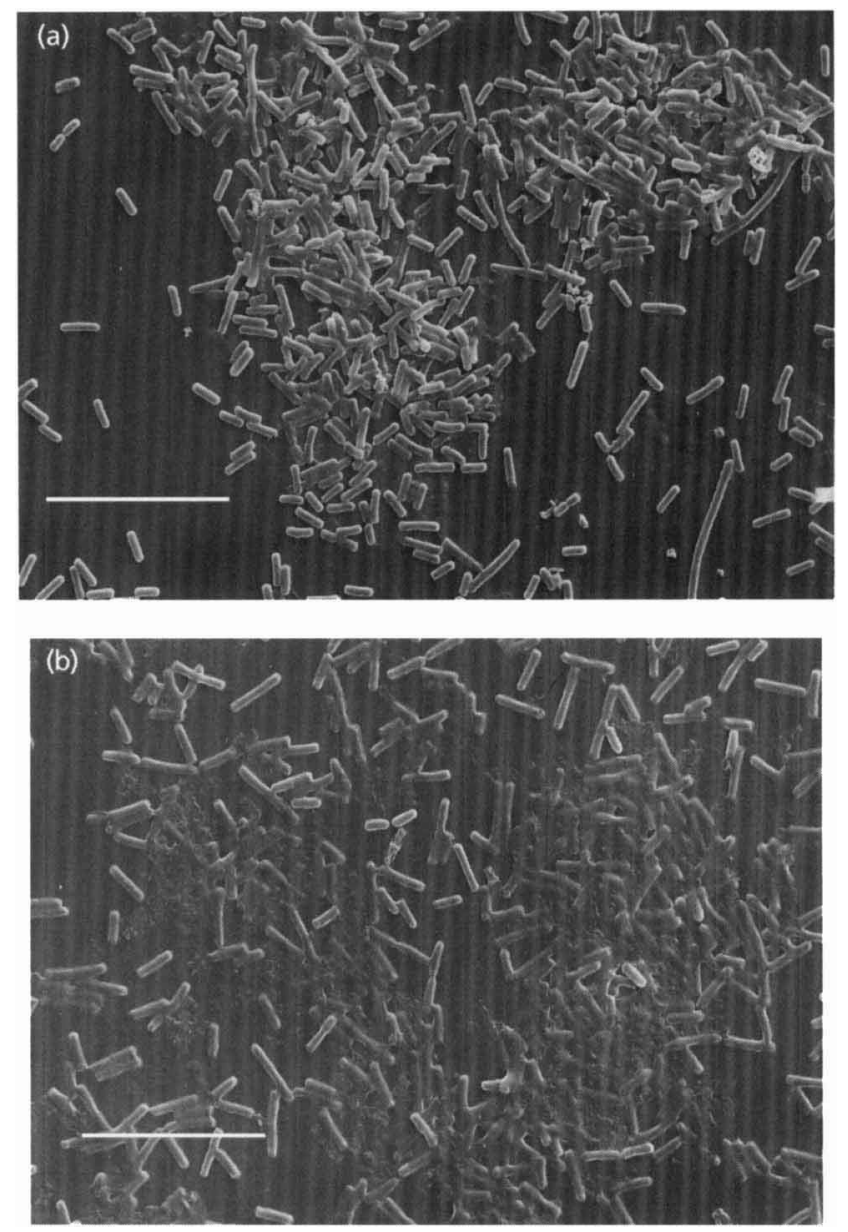

Fig. 4. Scanning electron micrographs of $B$. subtilis cells. (a) Untreated; (b) treated with $5 \mu \mathrm{M}$ Nva-FMDP for $30 \mathrm{~min}$. Bars, $20 \mu \mathrm{m}$.

Inhibition of peptidoglycan biosynthesis by Nva-FMDP was confirmed in another experiment where exponentially growing bacterial cells were labelled with DL-[1$\left.{ }^{14} \mathrm{C}\right]$-alanine. The incorporation was carried out in the presence of chloramphenicol to protect the cells from lysis and prevent incorporation of the label into cell proteins. Data presented in Fig. 2 show that Nva-FMDP, even at a concentration as low as $1 \mu \mathrm{M}$, effectively inhibited the incorporation of the radioactive label into peptidoglycan. The presence of $1 \mathrm{mM}$ GlcNAc partially reversed the inhibitory effect and $10 \mathrm{mM}$ GlcNAc prevented it almost completely.

One of the consequences of Nva-FMDP action on $B$. subtilis cells was a fast induction of bacteriolysis. As shown in Fig. 3(a), in the presence of $1 \mu \mathrm{M}$ Nva-FMDP cells continued to grow for about $30 \mathrm{~min}$, but then a decrease in the OD of the cell suspension, indicating lysis, was observed. The time to lysis became shorter at higher concentrations of Nva-FMDP, but it was never shorter than $15 \mathrm{~min}$, which corresponds to half the generation time for $B$. subtilis cells growing exponentially in MBD medium. It should be mentioned that while the lysis induced by Nva-FMDP at lower concentrations $(1-2 \mu \mathrm{M})$ was followed by partial re-growth, observed after 120-360 min, no such phenomenon was observed at Nva-FMDP concentrations $\geqslant 5 \mu \mathrm{M}$. In the presence of $1 \mathrm{mM}$ GlcNAc the time to lysis induced by $2 \mu \mathrm{M}$ Nva-FMDP was prolonged to $90 \mathrm{~min}$, while $10 \mathrm{mM}$ GlcNAc protected the cells against lysis.

The bacteriolysis caused by Nva-FMDP was compared to that induced by other cell-wall-acting antibiotics. Fig. 3 (b) shows that the bacteriolytic effect of $2 \mu \mathrm{M}$ NvaFMDP is comparable to that caused by cloxacillin and more pronounced than that exhibited by penicillin $\mathrm{G}$.

Lysis of B. pumilus cells induced by FMDP-dipeptides could be prevented by chloramphenicol, an antibiotic that inhibits protein biosynthesis in bacteria. However, in this case the time of addition was an important factor. As is shown in Fig. 3(c), $100 \mu \mathrm{g}$ chloramphenicol ml ${ }^{-1}$ added simultaneously with Nva-FMDP had no effect. On the other hand, addition of this antibiotic $15 \mathrm{~min}$ prior to Nva-FMDP almost completely prevented lysis and only growth inhibition was observed. According to current views, the bacteriolytic action of compounds inhibiting peptidoglycan biosynthesis is a consequence of induction of endogenous autolytic enzymes (Tomasz, 1979; Kitano \& Tomasz, 1979). It is therefore assumed that the primary effect of action of these antibacterial agents is growth inhibition and only the triggering of autolytic, cell-wall-degrading enzymes is responsible for the bactericidal effect (Rogers \& Forsberg, 1971). Our experiment provided evidence confirming this assumption in the case of the action of an agent inhibiting the earliest possible step in the peptidoglycan biosynthetic pathway.

Bacteriolysis of $B$. subtilis cells induced by Nva-FMDP was confirmed by scanning electron microscopy. Cells treated with the agent were collapsed and a massive amount of unidentified debris was observed (Fig. 4b), in contrast to normally shaped control cells (Fig. 4a). Similar changes have been noted using optical microscopy for glucosamine mutants of $B$. subtilis (Freese et al., 1970).

The complete reversibility of Nva-FMDP-induced growth inhibition and lysis points at GlcN-6-P isomerase as being the only enzyme important for the bacterial growth and viability that was inhibited upon the action of the FMDP-dipeptide. Such selectivity is surprising in light of the fact that GlcN-6-P isomerase is a member of the amidotransferase family, comprising several enzymes transferring an amino group from the $\gamma$-amido function of L-glutamine to different acceptors (Zalkin, 1993). FMDP, being a glutamine analogue, could theoretically interact with other amidotransferases. Indeed, another glutamine analogue, 6-diazo-5-oxo-Lnorleucine (DON) has been reported to show a pleiotropic effect. The bacteriostatic effect exerted by this agent could be prevented only by the simultaneous presence of GlcNAc and inosine, thus indicating that GlcN-6-P isomerase and any amidotransferase(s) involved in the purine biosynthetic pathway were targeted 
by DON (Coggin \& Martin, 1965). The selectivity of FMDP is therefore worth mentioning.

The following final conclusions based on the results of our studies presented above can be drawn. (1) The action FMDP-peptides against $B$. subtilis comprises three stages. (i) Rapid active transport into the cells, probably mediated by a di-tripeptide permease. (ii) Intracellular cleavage by any of the three $\mathrm{Mn}^{2+} / \mathrm{Co}^{2+}$ dependent peptidases. The rate of this process, much lower than that of uptake, seems to be the main factor determining the antibacterial activity of FMDP-peptides. (iii) Irreversible modification of GlcN-6-P isomerase by the released FMDP. The 'warhead' release is indispensable for its effect as an enzyme inactivator. (2) Irreversible blockage of GlcN-6-P isomerase results in a cessation of the intracellular pool of nucleotide precursors of peptidoglycan biosynthesis and triggers bacteriolysis. (3) GlcN-6-P isomerase is the only intracellular target important for cell growth and viability that is inhibited by FMDP.

\section{ACKNOWLEDGEMENTS}

This work was supported in part by the research grants from the Technical University of Gdańsk and the University of Camerino. The authors are grateful to Dr E. Insom from the Department of Zoology, University of Camerino for taking the scanning electronmicrographs.

\section{REFERENCES}

Andruszkiewicz, R., Chmara, H., Milewski, S. \& Borowski, E. (1986). Synthesis of $N^{3}$-fumaramoyl-L-2,3-diaminopropanoic acid analogues, the irreversible inhibitors of glucosamine synthetase. Int J Pept Protein Res 27, 449-453.

Andruszkiewicz, R., Chmara, H., Milewski, S. \& Borowski, E. (1987). Synthesis and biological properties of $N^{3}$-(4-methoxyfumaroyl)-L-2,3-diaminopropanoic acid dipeptides, a novel group of antimicrobial agents. J Med Chem 30, 1715-1719.

Andruszkiewicz, R., Milewski, S., Zieniawa, T. \& Borowski, E. (1990). Anticandidal properties of $N^{3}$-(4-methoxyfumaroyl)-L2,3-diaminopropanoic acid oligopeptides. $J$ Med Chem 33, 132-135.

Anraku, Y. (1980). Transport and utilisation of amino acids bacteria. In Microorganisms and Nitrogen Sources, pp. 9-33. Edited by J. W. Payne. Chichester: Wiley.

Atherton, F. R., Hall, M. J., Hassal, C. S., Lambert, R. W., Lloyd, W. J. \& Ringrose, P. S. (1979). Phosphonopeptides as antibacterial agents: mechanism of action of alaphosphin. Antimicrob Agents Chemother 15, 696-705.

Atherton, F. R., Hall, M. J., Hassal, C. S., Lambert, R. W., Lloyd, W. J., Ringrose, P. S. \& Westmacott, D. (1982). Antibacterial activity and mechanism of action of phosphonopeptides based on aminomethylphosphonic acid. Antimicrob Agents Chemother 22, 571-578.

Badet, B., Vermoote, P., Haumont, P. Y., Lederer, F. \& LeGoffic, F. (1987). Glucosamine synthetase from Escherichia coli: purification, properties and glutamine-utilizing site location. Biochemistry 26, 1940-1948.

Bauman, R. J., Bohme, E. H., Wiseman, J. S., Vaal, M. \& Nichols,
J. S. (1988). Inhibition of Escherichia coli growth and diaminopimelic acid epimerase by 3-chlorodiaminopimelic acid. $\mathrm{J} \mathrm{Biol}$ Chem 263, 1119-1123.

Berges, D. A., de Wolf, W. E., Dunn, G. L., Newman, D. J., Schmidt, S. J., Taggart, J. J. \& Gilvarg, Ch. (1986). Studies on the active site of succinyl-CoA:tetrahydropicolinate $\mathrm{N}$-succinyl transferase. J Biol Chem 261, 6160-6167.

Boisvert, W., Cheung, K. S., Lerner, S. A. \& Johnston, M. (1986). Mechanism of action of chloroalanyl antibacterial peptides. $J$ Biol Chem 261, 7871-7878.

Bradford, M. M. (1976). A rapid and sensitive method for the quantitation of microgram quantities of protein utilizing the principle of protein-dye binding. Anal Biochem 72, 248-254.

Chmara, H., Andruszkiewicz, R. \& Borowski, E. (1986). Inactivation of glucosamine-6-phosphate synthase from Salmonella typhimurium LT2 by fumaroyl diaminopropanoic acid derivatives, a novel group of glutamine analogs. Biochim Biophys Acta 870, 357-366.

Coggin, J. H. \& Martin, W. R. (1965). 6-Diazo-5-oxo-L-norleucine inhibition of Escherichia coli. J Bacteriol 89, 1348-1353.

Desmond, E. P., Starnes, W. L. \& Behal, F. J. (1975). Aminopeptidases of Bacillus subtilis. J Bacteriol 124, 353-363.

Dixon, M. \& Webb, E. C. (1979). The Enzymes. London: Longman Group.

Doi, E., Shibata, D. \& Matoba, T. (1981). Modified colorimetric ninhydrin methods for peptidase assay. Anal Biochem 118, 173-184.

Freese, E. B., Cole, R. M., Klofat, W. \& Freese, E. (1970). Growth, sporulation and enzyme defects of glucosamine mutants of Bacillus subtilis. J Bacteriol 101, 1046-1062.

Girodeau, J. M., Agouridas, C., Masson, M., Pineau, R. \& Le Goffic, F. (1986). The lysine pathway as a target for a new genera of synthetic antibacterial antibiotics? J Med Chem 29, 1023-1030.

Kahan, F. M., Kahan, J. S., Cassidy, P. J. \& Krop, H. (1974). The mechanism of action of fosfomycin. Ann NY Acad Sci 235, 364-370.

Kenig, M., Vandamme, E. \& Abraham, E. P. (1976). The mode of action of bacilysin and anticapsin and biochemical properties of bacilysin-resistant mutants. J Gen Microbiol 94, 46-54.

Kitano, K. \& Tomasz, A. (1979). Triggering of autolytic cell wall degradation in Escherichia coli by $\beta$-lactam antibiotics. Antimicrob Agents Chemother 16, 838-848.

Kucharczyk, N., Denisot, M.-A., LeGoffic, F. \& Badet, B. (1990). Glucosamine-6-phosphate synthase from Escherichia coli: determination of the mechanism of inactivation by $N^{3}$-fumaroyl-L2,3-diaminopropionic derivatives. Biochemistry 29, 3668-3676.

Laemmli, U. K. (1970). Cleavage of structural proteins during the assembly of the head of bacteriophage T4. Nature 227, 680-685.

Lugtenberg, E. J. J., de Haas-Menger, L. \& Ruyters, W. H. M. (1972). Murein synthesis and identification of cell wall precursors in temperature-sensitive lysis mutants of Escherichia coli. J Bacteriol 109, 326-335.

McCarthy, P. J., Newman, D. J., Nisbet, L. J. \& Kingsbury, W. (1985). Relative rates of transport of peptidyl drugs by Candida albicans. Antimicrob Agents Chemother 28, 494-499.

Mathiopoulos, C., Mueller, J.P., Slack, F. J., Murphy, C. G., Patankar, S., Bukusoglu, G. \& Sonenshein, A. L. (1991). A Bacillus subtilis dipeptide transport system expressed during early sporulation. Mol Microbiol 5, 1903-1913.

Milewski, S., Chmara, H., Andruszkiewicz, R. \& Borowski, E. (1985). Synthetic derivatives of $N^{3}$-fumaroyl-L-2,3-diaminopro- 
panoic acid inactivate glucosamine synthase from Candida albicans. Biochim Biophys Acta 828, 247-254.

Milewski, S., Andruszkiewicz, R. \& Borowski, E. (1988). Substrate specificity of peptide permeases in Candida albicans. FEMS Microbiol Lett 50, 73-78.

Milewski, S., Andruszkiewicz, R., Kasprzak, L., Mazerski, J., Mignini, F. \& Borowski, E. (1991). Mechanism of action of anticandidal dipeptides containing inhibitors of glucosamine-6phosphate synthase. Antimicrob Agents Chemother 35, 47-53.

Neuhaus, F. C. \& Hammes, W. P. (1981). Inhibition of cell wall biosynthesis by analogues of alanine. Phamacol Ther 14, 265-319.

Payne, J. W. (1972). The characterisation of dipeptidases from Escherichia coli. J Gen Microbiol 71, 267-279.

Payne, J.W. (1980). Transport and utilisation of peptides by bacteria. In Microorganisms and Nitrogen Sources, pp. 211-256. Edited by J. W. Payne. Chichester: Wiley.

Penefsky, H. S. (1977). Binding of $P_{1}$ to beef heart mitochondrial ATP-ase. J Biol Chem 252, 2891-2899.

Perego, M., Higgins, C. F., Pearce, S. R., Gallagher, M. P. \& Hoch, J. A. (1991). The oligopeptide transport system of Bacillus subtilis plays a role in the initiation of sporulation. Mol Microbiol 5, 173-185.
Rogers, H. J. \& Forsberg, C. W. (1971). Role of autolysins in the killing of bacteria by some bactericidal antibiotics. J Bacteriol 108, 1235-1243.

Tomasz, A. (1979). The mechanism of irreversible antimicrobial effects of penicillin. Annu Rev Microbiol 33, 113-137.

Ward, J. B. (1975). Peptidoglycan synthesis of L-phase variants of Bacillus licheniformis and Bacillus subtilis. J Bacteriol 124, 668-678.

Warren, L. (1972). The biosynthesis and metabolism of amino sugars and amino sugar-containing heterosaccharide. In Glycoproteins, pp. 1097-1126. Edited by A. Gottschalk. Amsterdam: Elsevier.

Vo-Quang, Y., Carniato, D., Vo-Quang, L., Lacoste, A. M., Nenzil, E. \& LeGoffic, F. (1986). ( $\beta$-chloro- $\alpha$-aminoethyl)-Phosphonic acids as inhibitors of alanine racemase and $\mathrm{D}$-alanine: $\mathrm{D}$-alanine ligase. J Med Chem 26, 148-151.

Zalkin, H. (1993). The amidotransferases. Adv Enzymol Relat Areas Mol Biol 66, 203-309.

Received 27 October 1997; revised 18 December 1997; accepted 6 January 1998. 